\title{
Financial solution for balancing global economy, poverty and hunger differences through blockchain secured real time traceability system
}

\section{Acharya Balkrishna}

Patanjali Research Foundation

Kavindra Singh

Bharuwa Solutions Pvt. Ltd.

Rishi Arya

Bharuwa Solutions Pvt. Ltd.

Pallavi Thakur ( $\nabla$ alubannu@gmail.com )

Patanjali Research Foundation

Shivam Singh

Patanjali Research Foundation

\section{Girish Ahuja}

Shri Ram College of Commerce

\section{Research Article}

Keywords: Finance traceability, project monitoring, loan underwriting, blockchain security system

Posted Date: April 19th, 2021

DOI: https://doi.org/10.21203/rs.3.rs-436957/v1

License: (1) This work is licensed under a Creative Commons Attribution 4.0 International License. Read Full License 


\section{Abstract}

The grave challenges of inequality, hunger and poverty are escalating in most of developing countries including India, thereby jeopardizing the overall growth of our country as well as the global economy. Under such crippling situations of poverty and inequality, the magnitude of inefficient and unsystematic lending practices, lack of monitoring by lenders and related fraudulent activities are on the rise, thereby causing a substantial build-up of non-performing assets as one of the emerging risks for the financial sector. The available finance management tools, in fact, lack the capability of real-time execution, fund deployment, credit risk assessment and project viability monitoring. This manuscript describes how a combination of process modeling, execution and measurement can be deployed for assessing financial traceability with accounting, billing, inventory \& real-time project tracking and monitoring updates. The explicit process accounts primarily for due diligence framework; controls financial traceability; as well as geo-mapping, fencing \& tagging based tangible process assessment of projects prior to lending, during and post implementation. Ultimately, the proposed blockchain secured finance solution (B-Bank ${ }^{T M}$ ) will cause optimization of credit risk capital at both stages of pre-sanction, pre-disbursement and post implementation of projects, thereby balancing and strengthening the financial institutions and ultimately the global economy.

\section{Highlights}

- A nation's financial institutions must attain economic sustainability by deploying well-established financial products with timely servicing, high repayment ratio, and low probability of defaults leading to non-performing assets.

- Projection Analysis for balancing poverty, inequality and sustaining economic growth also suggested that timely servicing, low delinquency, high repayment ratio for ensuring a low level of nonperforming assets has a significant role to play in strengthening the global economy.

- A real-time finance traceability system (B-Bank ${ }^{\text {TM }}$ ) can be adopted for ethically selecting the loan beneficiaries who are good or reasonably well performers and are low risk borrowers as based upon the real-time cash flow, project details and performance indicators

- Simulation matrix between Bank income to cost ratio \& NPA recovery percentage upon implementation of the real-time traceability tool suggested that the said tool, i.e., B- Bank ${ }^{\text {TM }}$ will escalate the regular and timely credit information sharing extent and NPA recovery percentage, thereby substantially increasing (may be doubling) the bank's income to cost ratio.

\section{Introduction}

The growing gap among rich and poor has become an arduous challenge for alleviating poverty and inequality, ultimately leading to an irrevocable damage to the global economy (Kim et al., 2018; Power, 2020). According to the United Nations Global Multidimensional Poverty Index (MPI) data, the global extreme poverty and income inequality is expected to rise even more in 2020 following the disruption of 
COVID-19 pandemic (Alkire et al., 2020). Similarly, according to the World Bank Development Research group data, there has been a substantial increase in the number of poor people pertaining to the COVID19 pandemic-related job losses and critical supply shortages (Solt, 2020; Timmermann, 2020). Countries where poverty and inequality rates have escalated beyond expectations accounts for more than 71 per cent of the global population, mainly belonging to the middle-income and developed countries (Duvendack \& Mader, 2020).

Amidst of such grave situations, finance or loan for a given project may be provided by different finance companies or banks, thereby extending a hand of support for the poor and unemployed citizens across the globe. However, the classical process of loan sanctioning is tedious and time taking, wherein an applicant needs to do lots of paperwork (Hainz \& Kleimeier, 2012). Nowadays, some finance companies and banks are accepting online loan applications, however, later they also require submission and verification of documents manually (Ganiger et al., 2017). Moreover, the conventional system does not connect finance companies/banks with the applicant directly till the completion of the project via online networking (Aladwani, 2001).

There exists a lack of real-time and verifiable information about the borrowers with the lenders and sponsors (Meralli, 2020). Such asymmetry of information may lead to the adverse selection of a nonworthy borrower who might misuse the borrowed funds and get involved in fraudulent practices of money laundering as well as finance terrorism (Von Thadden, 1999; Ennis \& Weinberg, 2013). Moreover, at times the financial institutions employ a third-party organization to conduct due-diligence and verification of the borrower's documents provided for loan sanctioning (Backer, 2017). This additional verification process adds up to the overall cost incurred to the bank, which ultimately gets reflected in the form of high interest rates and premium for the borrower.

Under such circumstances of data asymmetry and non-reliant information sources, it is likely that chances of adverse selection of risky borrowers as well as cases of misuse of funds will increase (Von Thadden, 1999). Both asymmetric selection and fund exploitation will fuel up the non-performing assets (NPA) crisis for financial institutions. Other accessory factors responsible for fueling the NPA crisis include the lack of detailed due diligence; lack of operational as well as financial transparency; and lack of stringent regulatory policies for loan repayment (Mittal, 2019). The ensuing section elaborates the various challenges faced by financial institutions across the globe.

\section{- Operational risks and Challenges for Financial Institutions}

According to the classical definition, non-performing asset (NPA) is a loan asset, which has ceased to generate any interest or repayment value for a bank (Singh, 2013). The challenge of non-performing loans has vexed the financial institutions all across the globe, and it has been burgeoning drastically ever since the crisis of COVID-19 pandemic (Wojcik \& loannou, 2020). It has been observed that the gross NPAs for banks across several hundreds of countries have collectively reached up to a level of 6.01 
percent. Particularly, in India, the gross NPA levels have increased enormously, thereby reaching the mark of INR 10.25 trillion as of March 2018 (Shinde \& Jagannathan, 2019; Jayaraman et al., 2019). As per RBI Financial Stability Report, 2020 , this NPA could rise to nearly $14.7 \%$ of the total loans in the coming years, pertaining to the economic stress imposed by Covid-19 pandemic (RBI Financial Stability Report, 2020). These NPAs are currently one of the biggest financial threats to the global economy and financial stability (Veerakumar, 2012).

Several economists and finance spokesperson have also stated the adverse effects of NPA on credit disbursements and economic growth. Dr. Arvind Panagariya, Ex- Vice Chairman of the NITI Aayog, 2016 and India's former Chief Economic Advisor, Dr. Arvind Subramanian, have also quoted that the escalating levels of NPAs will one day cripple the Central Government, thereby leading to a severe fall down in the national economy (Mittal, 2019).

An American economist, Nobel laureate Paul Krugman also has indicated that reckless lending by unworthy borrowers leads to an over-accumulation of NPAs. Such over-accumulation causes an overall decline in the economic growth at a global level (Pack \& Rivlin, 1992).

Mitigation of NPA related credit risks requires an exhaustive understanding of underlying factors responsible for intensifying the levels of NPA. Some of these factors include asymmetric \& incomplete information about borrower (information asymmetry \& adverse selection); misuse of funds (moral hazard); negligence in loan management \& repayment; uneven \& unreliable follow-up of borrower's project progress (no traceability); increased rate of interest with time; and unshared information of fraud borrower along the financial institutional network (in silos information) (Sinha, 2012). Ultimately the disadvantages of NPA for a financial institution include (i) a decrease in loan repayment by the borrower, translating into a decrease in net income for the bank; (ii) an overall reduced cashflow, leading to stagnancy in economic growth; and (iii) negative image creation of the respective bank/financial institution with high NPA ratio (Rao \& Patel, 2015; Golemi, 2015). Hence, it becomes imperative to control the levels of NPA for improving the health of the financial enterprises, thereby sustaining economic stability. The following sections describe the driving forces responsible for directly or indirectly fueling up NPA levels in the banking sector.

\section{- Customer Management}

In current financial market, the lenders rely primarily on the data provided by the prospective borrower, however, this data is often incomplete, wrongly inflated and fraudulent. As a consequence, the financial institutions might lack the necessary information for verifying the credit worthiness of the respective borrower, ultimately leading to credit riskiness and adverse selection. Additionally, the primary information about the borrowers is neither real time nor verifiable, thereby further burgeoning the whole issue of non-verified loan life cycle (Sinha, 2012). 


\section{- Lack of technological advancement}

In the current commercial lending market, most of the lenders use manual, paper-based loan underwriting \& approval practices. As a result, overall loan cycle becomes inconsistent, tedious, time consuming and uncertain. Technological automation is hence required to streamline the discordant financial system. Such advancements might aid in providing reliable and symmetric dataflow for the timely completion of the loan origination and approval process. There are several softwares available for automating the credit risk assessment and loan underwriting process, however, none of them are absolute in terms of real-time financial analysis and project monitoring (Hikida \& Perry, 2020).

\section{- Regulatory compliance concerns}

New policies for financial regulations in the banking and financial sector are continually being introduced, however, their stringent implication is yet fragmentary. Upon the implementation of the regulatory policies, the banks and financial institutions are supposed to spend a large amount of their discretionary budget on updating their flow of work in accordance with the regulatory compliance. However, this process is costly and complex. Overcoming the regulatory compliance problem requires an automated process of integration where technology can play a crucial role in aiding by providing automated reporting, real-time cashflow monitoring, and process streamlining applications (Benink \& Benston, 2005).

\section{- Credit risk analysis \& Covenant monitoring}

Financial institutions require credit history, transaction details and project analysis report for completing the loan underwriting process efficiently (Cremer, 2020). However, in the currently prevailing conventional underwriting process, there exists a dearth of routine finance and project monitoring practices. Comprehensive portfolio monitoring of beneficiaries is also not being done on a real-time basis. Moreover, the project balance sheet related data is not shared among the peer-to-peer financial network, thereby out ruling the chances of co-validation of the borrower. All such activities bring about ill practices of money laundering (misappropriation of funds by Kingfisher Airlines owned by Vijay Mallya), fake brand value creation (Fake fixed deposit receipts shown for Satyam Computer Services owned by Byrraju Ramalinga Raju) and sanction busting (fraudulent and unauthorized transactions done by Nirav Modi) (Sinha, 2012).

\section{- Available Solutions \& Gap analysis}


With the escalating global financial crisis, credit risk management still remains one of the biggest challenges for the financial institutions. Banking enterprises are uncertain about the unsecured lending, unwriting and non-performing assets (NPAs). Most optimum way of effectively mitigating these financial risks include extracting, transcribing, and reviewing credit information of the borrower's business projects (Golemi, 2015). Banking enterprises assess the credit worthiness of a borrower and his business by analyzing the background, capacity and capital investment associated with the said business project. However, absolute analysis and assessment of credit status is cumbersome due to the unavailability of real-time data of inventory stock, cashflow and financial projection of the given project (Chikan et al., 2018). Hence, it becomes imperative for the banking enterprises to conduct a real-time cashflow and sales trend analysis so as to determine the default risk associated with a loan borrowing company or individual.

There are many softwares and tools available for credit analysis conduction by banks, for e.g., Corniche, Finacle, CoBIS Microfinance Software etc. Every available banking tool either includes finance analysis or project progression analysis feature (Golin \& Delhaise, 2013), however, there is no such tool available till date that is absolute in terms of loan recoverability; financial record keeping with transparency; and credit decisioning as well as monitoring practices (Joseph, 2013). Moreover, the conventional systems do not store data in digital form and also there is no provision of tracing the complete history of previous financial transactions. Therefore, there is a need to introduce a system which is capable to cater to different requirements of different users on a real-time basis.

More recently, digital lending solutions have been introduced for potentially addressing credit-related challenges by speedily approving loans for worthy beneficiaries (Lokhande \& Zhende, 2020). Such digital solutions have quicker turnaround times and allows greater transparency of cashflow. These solutions include PoS lending which is a partnership model wherein the lenders can get connected with the borrowers for assessing the bank statements and online transaction history (Mangmang, 2018). However, there exists a gap in this digital framework as real-time tracking is yet intricate.

Several financial organizations have proposed to employ the loan service recharge feature based on the loan repaying tendencies of the borrower. It gives an additional benefit of additional loan credit to the borrowers, thereby promoting customer acquisition practices. In specific context, the Reserve Bank of India (RBI) has also introduced various financial instruments such as debt restructuring models and stressed assets refinancing solutions (Annual Report, 2005). However, all these efforts have gone in vain and exemplary NPA reduction has yet not been achieved.

In China, strengthened disclosure standards and regulatory reforms have been implemented for reducing the level of bad loans, if any. Several countries like Korea and Japan also have a specific Financial Supervisory Committee for ensuring a transparent scrutinizing system for supervising the finance and loan related issues. Similarly, all other countries across the globe are restructuring their debt-to-equity conversion mechanisms by implementing several regulatory measures, however, the implementation of such measures on a global scale is tedious (Kollman et al., 2011). 
Several other subjective solutions have also been proposed, such as development of a single 'bad-loan' bank in Spain; empowerment of public sector bank for collecting symmetric information in India; and creation of a loan fraud monitoring cell in Korea (Choudhary, 2020). Although these proposals are satisfactory, however, outright execution of these solutions is yet incomplete.

\section{- Need of the hour}

It is imperative to strengthen the functioning of financial institutions for ensuring the overall economic growth of a nation (Leeladhar, 2006). In present scenario, banks from all over the globe have been facing a serious problem regarding the recovery of disbursed loans. However, the ratio of Non-Performing Assets is ever-increasing thereby negatively impacting the performance, growth and profitability of financial institutions. Banks have deployed various measures for recovering the NPA by using channels such as Debt Recovery Tribunals, Credit Sanction Committees and invocation of several regulatory acts (Agrawal et al., 2017). However, all these solutions have turn out to be non-absolute, in effective and challenging to implement.

There exists a time lag in information flow about cash and transactions made by the borrowers. Also, there exists no mechanism of timely generation of warning signals for the fraudulent activities performed by a non-worthy borrower (Mannino, 2020). Hence, in such a scenario, fraudulent practices and cases of fund misuse cannot be traced efficiently. Under such circumstances, the need of the hour is to ensure proper evaluation of borrower's financial profile, followed by establishment of legitimate regulatory as well as legal advisory before sanctioning of loan to any borrower (Golemi, 2015).

Recently, in February, 2020, to mitigate the problems, the World Bank Group also called for proposals from all over the globe to develop a prototype build based upon blockchain and Distributed ledger technology (DLT) protocols for addressing the disbursement traceability of World Bank funded projects. Thus, the situation calls for a structured system of financial risk assessment and management by means of a technically advanced blockchain secured monitoring \& analysis solution. Such a solution would be comprehensive enough in facilitating the process of loan underwriting by implementing due diligence framework with e-KYC, distributed ledgers and cash flow monitoring.

Moreover, such a tool can be used for the real-time monitoring of project progression in diverse sectors including manufacturing, trading, services, agriculture \& dairy business. This solution should be designed in a way that it can be customized for any type of projects in diverse sectors, covering large scale business enterprises to SMEs, retailers \& entrepreneurs. Such a tool may aid in refining the supply chain and improving traceability and distribution management in manufacturing sector. Similarly, it may also improve accessibility by storing trading related data digitally that can be accessed with transparency by every party in the trading sector. It may also help in verifying and recording transaction data in a permanent way on a single, secure digital ledger shared by trusted counterparties across the services sector (Zambon, 2019). Retailers may also use this digital tool for implementing customer loyalty 
programs; increasing supply chain transparency; inventory management \& maintaining digital records (Saberi et al., 2019). Hence, such a holistic framework will aid in providing project progression data to the bank secured by blockchain implementation, thereby managing end-to-end loan origination, loan underwriting, lending and credit risk solutions for the banking enterprises (Abeyratne \& Monfared, 2016).

The present manuscript presents an integrative framework for real-time finance and project traceability assessment based on an extensive review of the factors and the essential elements. Implementation of such a comprehensive solution (B-Bank ${ }^{\mathrm{TM}}$ ) would be a step towards making the banks more profitable, valuable and controlling its NPAs, if any. Thereby ensuring that recent incidences of sudden collapse of PMC Bank, Yes Bank, Laxmi Vilas Bank, DHFL etc. happened in India are avoided with adequate early alarms and warning systems. There are several exclusive features of such an integrative tool that may differentiate it from all the other available softwares and tools. One such feature is the sharing of ledgers, financial statements and reports over blockchain secured platform, thereby providing copies of all the financial \& stock inventory related information to all the concerned stakeholders. Additionally, regular monitoring of inventory, stock aging details, receivables \& payables (both online \& offline sales) can be done as the data is updated on real time basis. Other additional features of this integrative framework might include user friendly (i) immutability feature that eliminates the need for multiple copies of the same documents being held; (ii) Automated due diligence and analysis of information for loan underwriting through secured blockchain; (iii) API intuitive feature that can be deployed in a scalable environment; \& (iv) cloud agnostic feature available on any network throughout the cloud.

\section{- Services to be offered by B-Bank ${ }^{\mathrm{TN}}$ - A Real-time finance and project traceability assessment tool}

The ensuing section describes the services that may be offered upon the implementation of B-Bank ${ }^{T M}$ which is a holistic framework of real-time finance and project traceability assessment tool (Patent Application No. 202011050665). B-Bank ${ }^{T M}$ will primarily provide an extensive system for real time tracking of projects by using Geo-tracking, fencing and tagging.

Simultaneously, B-Bank ${ }^{T M}$ will also provide a system for real time tracking of financial performance of the applicant after the loan disbursal. This tool may store all the project and cash flow related data digitally and make the stored data available in a real-time basis, thereby connecting the financial service providers and applicants continuously till completion of the project. Hence, this tool will ultimately aid in generating trust between the financial service providers and applicants, thereby facilitating better customer acquisition.

One of the most important advantages of B-Bank ${ }^{\mathrm{TM}}$ is the potential cost reduction by not requiring installation and support of additional hardware and software. The configuration module of B-Bank ${ }^{\mathrm{Tm}}$ shall include many common options including ledger sharing, easy transaction settlement, document immutability, and real-time sales as well as inventory updates. 
Further integrations of standalone features can also be provided by the financial institutions to its clients, such as micro-ATM services, wherein, a Cash at POS facility will be available that allows debit card holders to withdraw cash by swiping their card at the merchant's POS terminals. B-Bank ${ }^{\mathrm{TM}}$ may also allow clients to pay their utility bills \& conveniently transfer money in a secured manner. Clients can use it to self-pay \& settle all accounts themselves as it will support all digital payment modes. Moreover, an Aadhar enabled or Social Security number-based payment system may also be integrated for allowing the merchant to accept payment from a customer of any bank, by authenticating the customer's Aadhaar enabled bank account details. Ultimately, the said tool may allow the creation of custom changes \& bill cycles with complete flexibility \& traceability in a secured manner.

B-Bank ${ }^{\text {TM }}$ will have multiple modules for benefitting customers, bank enterprises nationwide. Customers will get benefitted by employing this tool as it aids in managing personal data and financial statements of all their clients. Assessment of the financial data ultimately also allows each client to measure its financial risk. Other related features for the customers include payment records, which allows one to see the evolution of payments and incidents related with them; and the status of payment of each customer's invoices.

Further, such a module will contain services for detecting and resolving issues related with billing. It may purposely send notifications of payments whose due date has expired (by email and text). Ultimately, this tool will generate multiple reports detailing the invoices, sales and inventory. All the aforementioned features have been summarized in Fig. 1.

On a national level, this tool will aid in building trust with citizens by maintaining transparency through decentralization of data, thereby ultimately improving the national economy by means of increasing enterprise efficiency.

\section{- Blockchain enabled optimization of loan cycle - Algorithm employed in the working of B-Bank ${ }^{\mathrm{TN}}$}

The proposed algorithm for B-Bank ${ }^{\mathrm{TN}}$ - a blockchain based real time traceability system will include API based automation, transaction monitoring, project progress tracking, auto- decisioning and portfolio risk management features. Such a tool will also be integrated at the back-end with ERP (Enterprise Resource Planning), POS (Point-of-Sales), DMS (Distribution Management System), WMS (Warehouse Management System) and CRM (Customer Relationship Management) software applications. Moreover, a customizable option of partly integrating the previously running software applications can also be appended, wherein the user can employ other tools in place of the back-end integrations.

The algorithmic flow will begin from the first step of customer management wherein an API based automated loan origination platform will deploy the services of symmetric information collection about the borrower's profile. Thereafter, credit risk analysis will be performed on the basis of daily transaction monitoring and sales cash flow traceability, as integrated with back-end POS (Patent Application No. 
201911012090). All the collected information relating to the borrower's profile and cash flow will be shared with the financial institution as well as the peer-to-peer group through blockchain secured platform.

Upon critical and thorough assessment of the shared documents, the financial institution will either approve or decline the loan application. In this regard, threshold parameters will also be set up in the back-end system so as to generate an auto-decision based on the provided documents and traced cash flow.

Thereafter, post disbursement monitoring of the allocated funds will be accomplished by means of tracking the inventory stock (mediated by WMS); distribution and sales of goods (mediated by DMS); sales and purchase cash flow (mediated by POS); and GIS/GPS based real-time visualization of project progress (Patent Application No. 201911046328). A chronological record of the audit trail of every transaction can also be monitored through the B-Bank ${ }^{\mathrm{TM}}$ interface. Such an audit trail will be immutable and hence would mitigate any chances of fraudulent modifications in accounting entries. Recently, the Ministry of Finance, Government of India, has also mandated the business institutions to use accounting softwares with audit trail capabilities inbuilt, w.e.f. April $1^{\text {st }} 2022$ (Business Today, 2021). The present software $\mathrm{B}-\mathrm{Bank}^{\mathrm{TM}}$ is an audit trail compliant tool which conforms to the financial requirements of the Government of India in order to subdue the potential financial frauds, if any.

Such a detailed monitoring of the allocated funds will aid in assessing the risk associated with loan sanctioning, if any. Hence, portfolio risk management of the running projects will be done on a real-time basis, thereby generating any red flags timely. The detailed possible algorithm of work flow of B-Bank ${ }^{\text {Tm }}$ has been summarized in Fig. 2. In this way, implementation of such a framework will entail complete traceability of borrower's information and project progress, thereby optimizing the complete loan cycle. The technological advancements of API integration, blockchain based data storage, auto-decisioning and ERP integrations will aid in strengthening the financial institutions, thereby leveraging the whole economy by out ruling the probability of NPA to the maximum extent. Such reinforcement of the economy will ultimately aid in eradicating the social stigmas of poverty and inequality.

\section{Material \& Methods}

Data relating to the poverty, inequality, economic growth, NPA and credit information were collected and documented using the global economy databases (Supplementary Table 1). Relationship between all these variables were understood with the aid of a correlation matrix as prepared by using GraphPad Prism software (GraphPad Software, La Jolla, California). On the basis of the Pearson correlation 
coefficient, measure of the linear association between two variables were quantified and the value fell between -1 to 1 . A negative value indicated a perfectly negative linear correlation; 0 indicates no correlation; and a positive integral value indicates a perfectly positive linear correlation between the said variables. All the computed coefficients were plotted in a common matrix so as to understand the relevance of NPA recovery for diminishing poverty and income inequality, thereby bringing about a transformation in the global economy.

\section{Results \& Discussion}

NPA was found to be positively correlated with inequality index $(r=0.82)$ as well as poverty \& hunger index $(r=0.51)$. Moreover, the growth of overall economy is negatively correlated with NPA $(r=-0.47)$, thereby establishing the fact that the reduction of NPA levels is imperative for expansion of economy and strengthening of the fiscal conditions. Additionally, there exists a negative correlation between NPA and credit information sharing $(r=-0.12)$ as well as bank income to cost ratio $(r=-0.78)$. This gives an insight to the fact that NPA levels may get declined if the credit information of the borrower's is pertinently shared amongst the financial stakeholders, thereby escalating the bank's overall income to cost ratio. The complete correlation matrix has been elucidated in Fig. 3a.

Furthermore, the cumulative trend of index percentages of NPA \& other fiscal parameters was plotted to analyze the prevailing trends and extrapolate the choicest values of all the respective indices. Such preferred values can only be attained if an information traceability framework such as B-Bank ${ }^{T M}$ is implemented for real-time tracking of the borrower's information and project progress, thereby optimizing the complete loan cycle. The value projection trend suggests that the cumulative level of NPA will rise from $9.23-15 \%$ in the year 2020. Such an escalation in NPA will pose an impact on poverty \& hunger index as it will show an increase of nearly $8.75 \%$. Similarly, inequality index will also show an increase from 56.17 in 2019 to $56.77 \%$ as projected in 2020 . All such escalations will ultimately cause the economic growth to hamper and fall down by nearly 3.5 folds. In fact, all these prevailing transgressions can be managed if the credit information sharing ratio is escalated by nearly 1.5 folds. This shows that the even a slight transparency in the data sharing framework will embark comprehensibility in the entire system, thereby ultimately expanding the realm of bank income to cost ratio ( 49.96\%) and NPA recovery percentage ( 1.5 folds increase). The complete projection analysis has been elucidated in Fig. $3 b \& 3 c$.

Simulation matrix also suggested similar results, wherein implementation of a blockchain secured real time traceability system with decentralized credit information (B-Bank $\left.{ }^{\mathrm{TM}}\right)$ will lead to a faster and preponderant NPA recovery. It has been simulated that a 1-fold increase in the credit information sharing percentage will lead to 2.25 folds increase in the NPA recovery (Fig. 3d). Further simulation runs also confirmed that such an increase in the NPA recovery percentage upon implementation of the proposed tool will lead to a maximum bank income to cost ratio of nearly $55.75 \%$ (Fig. 3e). 
The aforementioned results are based upon the empirical extrapolation and simulation studies. The approach presumes that the available data is proportionally constant with minimal variations. However, in real scenarios, random variations may creep in, thereby yielding somewhat different outcome. Under real situations, the projected trend will not shift drastically, but may show some variations.

Additionally, it must be noted that the present study outlines the projection analysis for a 10-year time span of Indian economy (2011-2020). It doesn't represent the global data as it would be too complex and insufficiently large to handle. However, the projected trend can easily be replicated for any countryspecific data, thereby giving an overall picture of the ever-changing financial and fiscal trends upon implementation of a blockchain secured real-time financial traceability system.

\section{Conclusions}

The economic sustainability of a Financial institution / nation is fostered by well-established risk averse financial products with high repayment ratio, and low bank cost to income ratio. However, there are several gaps in the financial framework including data asymmetry, adverse selection, time delay in information availability and moral hazard which further leads to increasing non-performing assets. The authors propose that the current regulatory frameworks need to be strengthened by employing new age and innovative technologies like GIS/GPS enabled project tracking, blockchain technology mediated information decentralization, and seamless back-end integrations with available softwares. Need of the hour is to develop a robust and secure finance monitoring system to be deployed at the financial institutions for sharing transactions, project details, contracts and pledge/mortgage details with transparency among all the stakeholders. Implementation of such a tool will ensure improved governance and regulatory framework with stringent disclosure requirements. Such a tool will be highly customizable and can easily be adopted for at common platforms across the financial services industry. A similar kind of technological framework, namely, B-Bank ${ }^{\text {TM }}$, has been designed by Bharuwa Solutions Pvt. Ltd. (IT Service \& Software Development company) and it will aid in real-time credit assessment, conclusive due diligence and detailed pre-\& post disbursement monitoring. The said tool is being tried and tested on a pilot scale and will soon be deployed in a large-scale manner across the country. It is assumed that adoption of an end-to- end financial solution in the form of a technological tool will ultimately aid in selecting the worthiest beneficiaries for providing loans as based upon the real-time cash flows and project details, thereby ruling out the chances of money laundering and finance manipulation including flow of funds to illegal activities like narcotics activities, tax evasion, terrorism etc. Ultimately, such a tool will aid in improving the overall economic situation of the world by balancing global economy, poverty and hunger differences.

\section{Declarations}

Author Contributions: AB conceived the presented idea and developed the theory. KS, RA PT and SS analyzed the available data and co-wrote the paper. GA investigated and supervised the findings of this work. $A B$ and $G A$ provided critical revision of the article and approved its final version for submission. 
Funding: This research received no external funding and funded by internal funds of Patanjali Research Foundation Trust, Haridwar, India.

Acknowledgments: The authors are humbly grateful to Swami Ramdev for institutional and research supports. The authors also gratefully acknowledge the efforts of all the colleagues of the Bharuwa Solutions Pvt. Ltd. and Patanjali Research Group for their help in data collection.

Conflicts of Interest: The authors declare no conflict of interest.

\section{References}

Abeyratne, S. A., Monfared, R. P., 2016. Blockchain ready manufacturing supply chain using distributed ledger. Int. J. Res. Eng. Technol. 5(9), 1-10.

Agrawal, G. P., Swain, A. K., Bhuyan, A. K., 2017. Corporate debt restructuring in scheduled commercial banks in India: An analysis. Int. J. Res. Granthaalayah. 5(2), 92-112.

Aladwani, A. M., 2001. Online banking: a field study of drivers, development challenges, and expectations. J. Inf. Manag. 21(3), 213-225.

Alkire, S., Kanagaratnam, U., Suppa, N., 2020. The global Multidimensional Poverty Index (MPI) 2020. OPH I MPI Methodological Note 49, Oxford Poverty and Human Development Initiative, University of Oxford. (Accessed on 28th Nov, 2020) -https://ophi.org.uk/multidimensional-poverty-index/

Annual Report - Department of Economic Affairs, 2005. India: Government of India, Ministry of Finance. (Accessed on 30th Nov, 2020) - https://dea.gov.in/annual-reports/annual-reports-archive

Backer, L. C., 2017. The Corporate Social Responsibilities of Financial Institutions for the Conduct of Their Borrowers: The View from International Law and Standards. Lewis \& Clark L. Rev. 21, 881-913.

Benink, H., Benston, G., 2005. The future of banking regulation in developed countries: Lessons from and for Europe. Financ. Market Inst. Instrum. 14(5), 289-328.

Business Today, 2021. Govt extends implementation of mandatory audit trail of companies' accounts till Apr 1, 2022. (Accessed on $1^{\text {st }}$ April 2021) - https://www.businesstoday.in/current/economy-politics/govtextends-implementation-of-mandatory-audit-trail-of-companies-accounts-till-apr-1-

2022/story/435507.html

Chikan, A., Kovacs, E., Matyusz, Z., Sass, M., Vakhal, P., 2018. Inventories in National Economies: A CrossCountry Analysis of Macroeconomic Data. Springer.

Choudhary, R., 2020. Bad loan in Indian banks: Hustle in bank growth. Int. J. Finance Manage. Econ. 3(1): 16-21. 
Cremer, L., 2020. Underwriting Limits and Optimal Leverage in Commercial Real Estate. J. Real. Estate. Finance Econ. 60(3), 375-395.

Duvendack, M., Mader, P., 2020. Impact of financial inclusion in low-and middle-income countries: A systematic review of reviews. J. Econ. Surv. 34(3), 594-629.

Ennis, H. M., Weinberg, J. A., 2013. Over-the-counter loans, adverse selection, and stigma in the interbank market. Rev. Econ. Dyn. 16(4), 601־616.

Ganiger, N., Swathi, M., Vishrutha, K., Gorthi, C., TG, K., 2017. Online loan application and verification for personal loan. J. Innov. 6(5), 9706-9710.

Golemi, E., 2015. Excessive Credit Growth-An Early Indicator of Financial Instability. Eur. J. Econ. Bus. 1(2), 174-179.

Golin, J., Delhaise, P., 2013. The bank credit analysis handbook: A guide for analysts, bankers and investors. John Wiley \& Sons.

Hainz, C., Kleimeier, S., 2012. Political risk, project finance, and the participation of development banks in syndicated lending. J. Fin. Int. 21(2), 287-314.

Hikida, R., Perry, J., 2020. FinTech Trends in the United States: Implications for Household Finance. Pub. Policy Rev. 16(4), 1-32.

Jayaraman, T. K., Lee, C. Y., \& Ng, C. F., 2019. The Causal Factors behind Rising Non-performing Assets of India's Commercial Banks: A Panel Study. Adv. Pacific Basin Bus. Econ. Finance 7, 201-212.

Joseph, C., 2013. Advanced credit risk analysis and management. John Wiley \& Sons.

Kim, H., Huh, S., Choi, S., \& Lee, Y., 2018. Perceptions of inequality and attitudes towards redistribution in four East Asian welfare states. Int. J. Soc. Welf. 27(1), 28-39.

Kollmann, R., Enders, Z., \& Muller, G. J., 2011. Global banking and international business cycles. Eur. Econ. Rev. 55(3), 407-426.

Leeladhar, V., 2006. Taking banking services to the common man-financial inclusion. Reserve Bank of India Bull. 60(1), 73-77.

Lokhande, M. Y. Y., \& Zhende, M. A. S., 2020. "The study of Opportunities \& Challenges of Technology to use in Banking Sector". Stud. Indian Place Names 40(11), 315-318.

Mangmang, G., 2018. Development and Implementation of Point of Sale System (POS): Profitability Measurement for Retail Business. J. Educ. Hum. Resour. Dev. 6, 220-226.

Mannino, E. F., 2020. Lender liability and banking litigation. Law Journal Press. 
Meralli, S., 2020. Privacy-preserving analytics for the securitization market: a zero- knowledge distributed ledger technology application. Financ. Innov. 6(1), 1-20.

Mittal, B., 2019. The Snowball Effects of NPA on Indian Economy. J. Guj. Res. Soc. 21(9), 120-137.

Power, S. A., 2020. Why a richer world will have more civic discontent: The infinity theory of social movements. Rev. Gen. Psychol. 24(2), 118-133.

Rao, M., \& Patel, A., 2015. A study on Non-performing assets management with reference to public sector banks, private sector banks and foreign banks in India. J. Manag. Sci. 5(1), 30-43.

Reserve Bank of India., 2020. RBI Financial Stability Report, Issue No. 21. (Accessed on 28th Nov, 2020) https://rbidocs.rbi.org.in/rdocs/PublicationReport

Saberi, S., Kouhizadeh, M., Sarkis, J., \& Shen, L., 2019. Blockchain technology and its relationships to sustainable supply chain management. Int. J. Prod. Res. 57(7), 2117-2135.

Shinde, C. P., \& Jagannathan, U. K., 2019. A study on past trends, causes and future trajectory of NPA in Indian banking sector. Int. J. Multidiscip. Res. 9(10), 34-46.

Singh, A., 2013. Performance of non-performing assets (NPAs) in Indian Commercial Banks. Int. J. Mark. Financ. Serv. Manag. Res. 2(9), 86-94.

Sinha, A., 2012. Striking a Balance: Credit Penetration and NPA Management- Role of Information Sharing. RBI Bull. April, 717-724.

Solt, F., 2020. Measuring income inequality across countries and over time: the standardized world income inequality database. Soc. Sci. Q. 101(3), 1183-1199.

Timmermann, C., 2020. Epistemic ignorance, poverty and the COVID-19 pandemic. Asian Bioeth. Rev. 12, 519-527.

Veerakumar, K., 2012. Non-performing assets in priority sector: A threat to Indian scheduled commercial banks. Int. Res. J. Finance Econ. 93(1), 6-23.

Vijayalakshmi, N., 2016. Non-performing assets in public and private sector banks-A comparative study. Alochana Chakra 9(8), 1404-1411.

Von Thadden, L., 1999. Money, inflation, and capital formation: an analysis of the long run from the perspective of overlapping generations models (479). Springer Science \& Business Media.

Wojcik, D., \& loannou, S., 2020. COVID-19 and Finance: Market Developments So Far and Potential Impacts on the Financial Sector and Centres. Tijdschr. Econ. Soc. Geogr. 111(3), 387-400. 
Zambon, I., Cecchini, M., Egidi, G., Saporito, M. G., \& Colantoni, A., 2019. Revolution 4.0: Industry vs. agriculture in a future development for SMEs. Processes 7(1), 1-16.

\section{Abbreviations}

API: Application Programming Interface; CRM: Customer Relationship Management; DHFL: Dewan Housing Finance Corporation Limited; DLT: Distributed Ledger Technology; DMS: Distribution Management System; ERP: Enterprise Resource Planning; KYC: Know Your Customer; NPA: NonPerforming Assets; PMC: Punjab and Maharashtra Co-operative; POS: Point-of-Sales; WMS: Warehouse Management System; RBI: Reserve Bank of India; SME: Small and Medium-sized Enterprises.

\section{Figures}




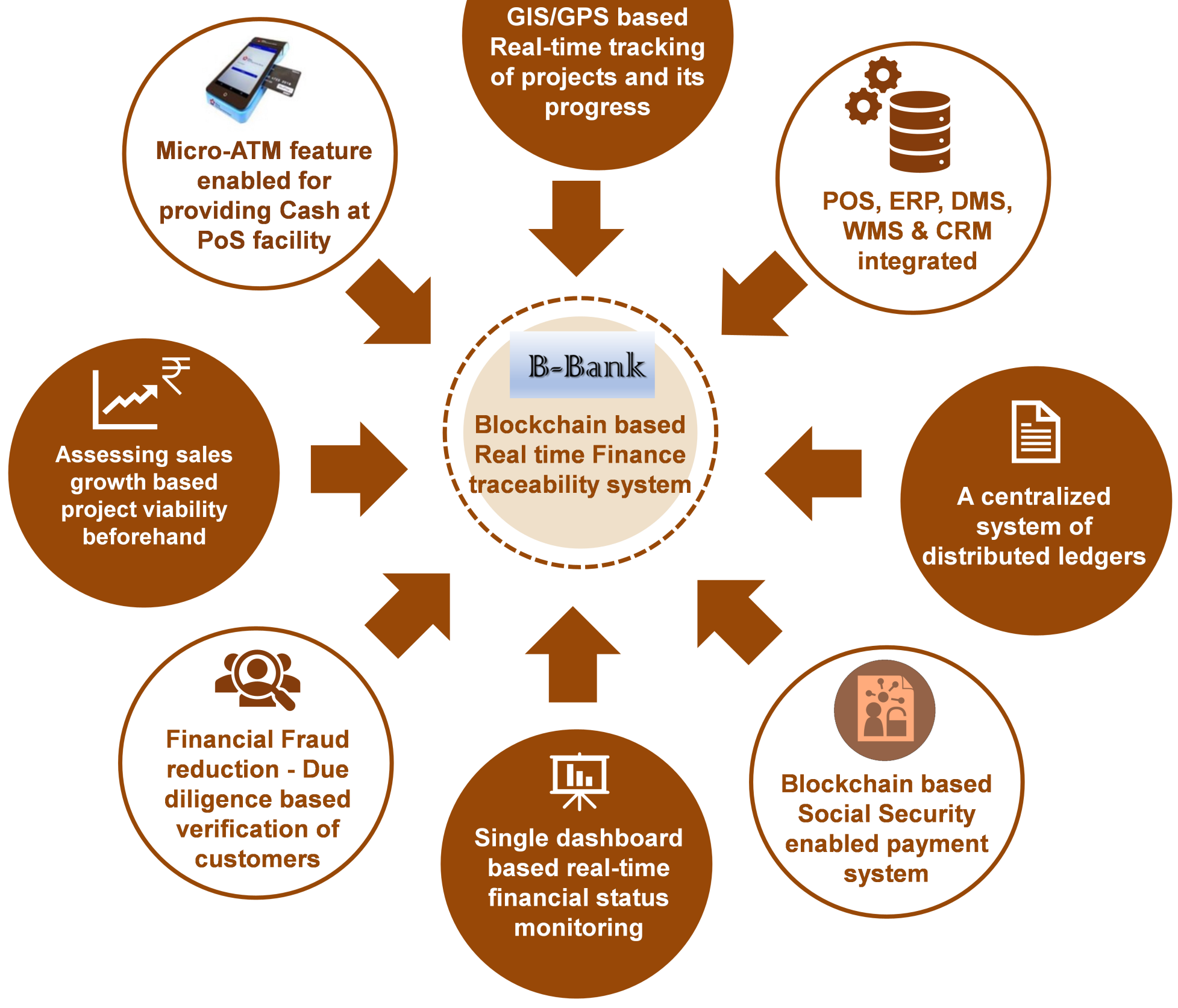

Figure 1

Blockchain based Real-time Finance traceability system - Services \& Solutions for facilitating Loan traceability \& Customer acquisition 


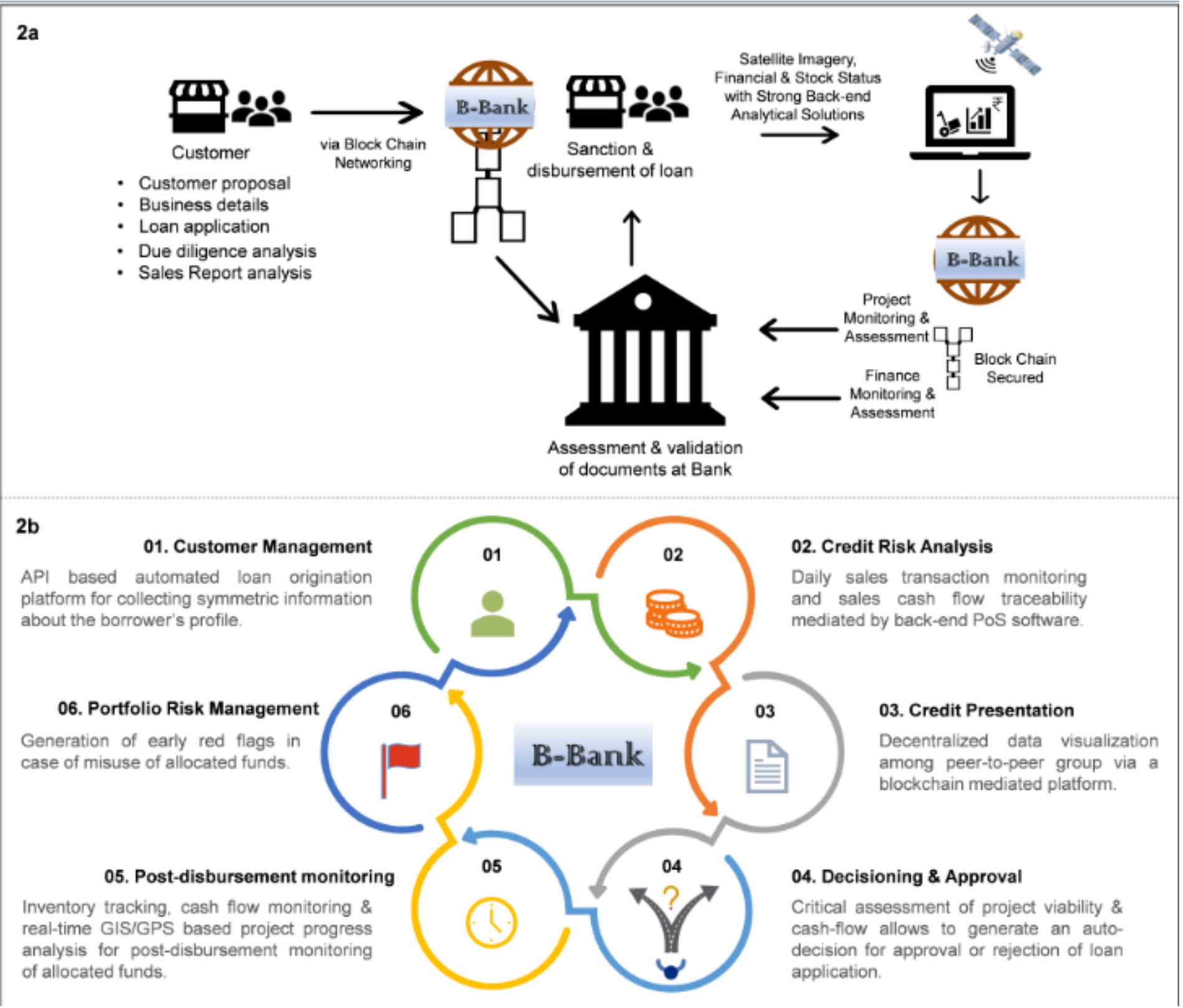

Figure 2

B-BankTM - An End-to-End Financial Solution: (a) Customer's profile is transferred to the financial enterprises as mediated by a blockchain secured traceability solution. The profile is verified by the bank/financial institution, thereafter the sanction, if approved, is disbursed. Consequently, real-time tracking of finance and inventory stock is also done as mediated by cashflow monitoring and satellite imagery-based analysis. Thereafter, the business project and finance related data is passed onto the bank for further portfolio risk assessment. (b) Optimization of loan cycle via a blockchain enabled tool. 
3a
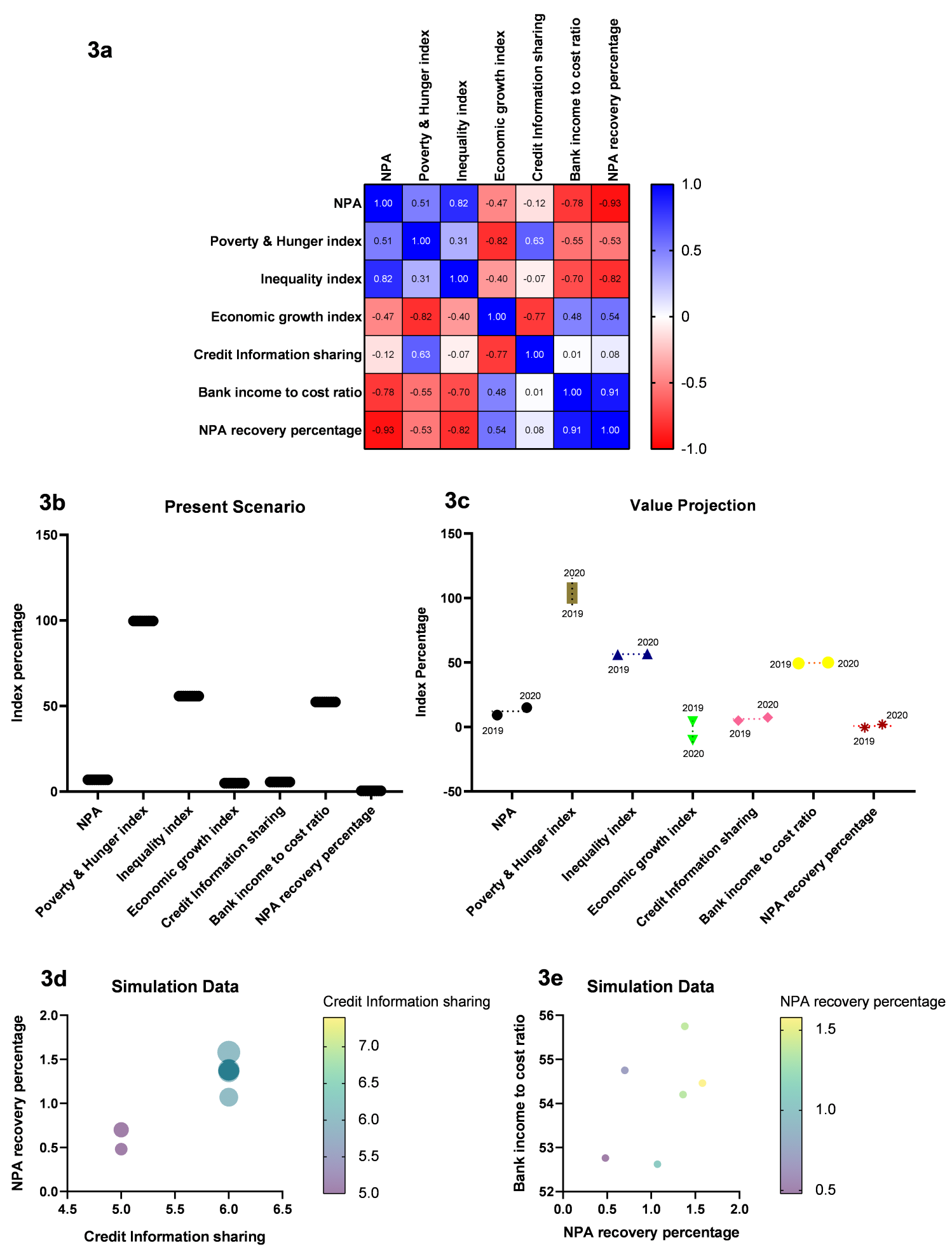

\section{Figure 3}

Projection Analysis - (a) Correlation matrix; (b) Cumulative trend of index percentages of NPA \& other fiscal parameters; (c) Projection analysis of extrapolated data; (d) Simulation matrix between NPA recovery percentage \& Credit information sharing; (e) Simulation matrix between Bank income to cost ratio \& NPA recovery percentage. 


\section{Supplementary Files}

This is a list of supplementary files associated with this preprint. Click to download.

- SupplementaryTable1.docx 